\title{
Sustainability Issues of the Association for Engineering Education in Southeast Asia, East Asia and the Pacific (AEESEAP) Activities
}

\author{
Nasrudin Abdul Rahim, Suhana Mohd Said \\ Department of Electrical Engineering \\ Faculty of Engineering \\ University of Malaya 50603 \\ Kuala Lumpur, Malaysia \\ nasrudin@um.edu.my
}

\begin{abstract}
The Association for Engineering Education in Southeast Asia, East Asia and the Pacific was established with the aim to improve the education of engineers and technologists in its member countries. This paper will give an overview of AEESEAP objectives and its current activities, coordinated by the current secretariat based in Malaysia. The main issue being dealt with throughout the existence of AEESEAP is the issue of sustainability of the association. This paper will highlight the objectives and current activities of AEESEAP, with regards to sustaining this association.
\end{abstract}

\section{Background of AEESEAP}

The idea for a regional association for engineering education was first conceived at the UNESCO Regional Seminar on New Approaches to Engineering Education in Asia, held at the University of Malaya in Kuala Lumpur during March 9-13,1970. During this seminar, it was recommended that a permanent organisation for Engineering Education for the Southeast Asia region should be formed. The objective of this organization is to provide a platform for the exchange of ideas on new approaches and developments in Engineering Education.

This proposal was followed by a meeting at the UNESCO Field Service Office in Jakarta, which was sponsored by UNESCO and the World Federation of Engineering Organizations (WFEO. This meeting was attended by representatives from Australia, Indonesia, New Zealand, Malaysia, Japan, the Philippines, Singapore and Thailand. The Association for Engineering Education in South East Asia (AEESEA) was established. Its composition and aims was outlined in a constitution which upheld the resolutions formulated during the Regional Seminar of 1970 .

The inaugural meeting of AEESEA was held at the College of Engineering, University of the Philippines in Manila during October 18-19, 1973 in conjunction with the UNESCO regional seminar on Education, Industry Cooperation and Training. In 1989, the name of the association was changed to the Association of Engineering Education in South East Asia, East Asia and the Pacific (AEESEAP), to comprehensively reflect the region of the member countries. Currently, there are 15 voting members of the AEESEAP. The activities of AEESEAP are regulated by a secretariat, which is rotated between the voting member countries every 3 years.

\section{Aims and objectives of AEESEAP}

AEESEAP aims to improve the quality of the education of engineers and technologists in the member countries within the Southeast Asia, East Asia and the Asia Pacific region, in an effort to aid the development of engineering and technology in these countries. The association seeks to:

- Provide a common platform which will assist in enhancing networking and cooperation between engineering education institutions, industry and professional bodies related to engineering education in the region.

- Promote the development of systems and standards for engineering and technology education. 
The establishments of these goals were with the intention of engineering and technology, which is seen to be a main driver in the economic development in the region, which in turn will improve the quality of life. This Association's activities have been consistently geared towards achieving these goals since its inception in 1973.

The Aims of AEESEAP are as follows:

- To help formulate and deliver high quality curricula in engineering education

- To organise and facilitate training programmes for engineering educationists and technologists

- To assist in training engineering graduates who are aware of the role of engineering within in society, in developing wealth and enhancing the quality of life within the society

- To disseminate information and encourage participation within member countries, regarding collaborative efforts and availability of international assistance programmes for engineering education.

- To actively and continuously identify current problems in engineering education, and to find the solutions to these problems through shared expertise between members.

- To provide consultancy services regarding improving the quality of engineering education programmes

- To provide expert advice and training regarding the establishment of new engineering education institutions, and the upgrade of existing ones.

- To promote a "lifelong learning" attitude, by providing programmes for continuing education and professional development for engineering educators, engineers and technologies, through collaborative effort between engineering education institutions, industry and professional societies.

- To promote cooperation between industry and educators on a national and international basis.

- To assist existing national societies of engineers and engineering technicians and groups of educators of engineers and engineering technicians in their efforts to improve engineering education.

- To assist in the establishment of societies or groups of engineering technicians for this purpose where they do not already exist.

\section{AEESEAP Membership}

AEESEAP is open to membership from organisations (government, industry and non-governmental organisations) and individuals in the countries of Southeast Asia and the Pacific who are dedicated to the cause of developing and promoting engineering education. The association has one voting member from each associated nation. These include Australia, Brunei, Fiji, Indonesia, Japan, Korea, Lao P.D.R, Malaysia, New Zealand, Papua New Guinea, P.R. China, Philippines, Singapore, Thailand and Vietnam.

The composition and the summary of AEESEAP membership as of August 2000 are as follows:

\begin{tabular}{|c|c|}
\hline Membership Category & Number of Members \\
\hline \hline Voting Member & 15 \\
\hline Ordinary & 131 \\
\hline \hline Individual & 30 \\
\hline \hline Supporting & - \\
\hline \hline Correspondent & - \\
\hline \hline Honorary & 16 \\
\hline \hline Subscribing Library & 20 \\
\hline Total & 212 \\
\hline
\end{tabular}


The voting members are:

- VM001 Institution of Engineers, Australia (IEAust) - Australia

- VM002 Institution of Engineers, Indonesia (PII) - Indonesia

- VM003 Japanese Society for Engineering Education (JSEE) - Japan

- VM004 Korean Society for Engineering Education \& Tech Transfer (KSEETT) -Korea

- VM005 Center for Communication \& Transport - Lao PDR

- VM006 University of Malaya - Malaysia

- VM007 Institution of Professional Engineers, New Zealand (IPENZ) - New Zealand

- VM008 PNG University of Technology - Papua New Guinea

- VM009 College of Engineering, University of the Philippines - Philippines

- VM010 Engineering Institute of Thailand (EIT) - Thailand

- VM011 Vietnam Union of Science \& Technology Associations (VUSTA) - Vietnam

- VM012 Chinese Assoc for Continuing Engg Educ. (CACEE) - PR of China

- VM013 Institut Teknologi Brunei - Brunei Darussalam

- VM014 National University of Singapore - Singapore

- M015 Fiji Institute of Technology - Fiji

For sustainable development in the field of Engineering Education in the region, it is the goal of each Member Institution to participate in the activities which contribute to the achievement of the objectives elaborated in Section 2.0.

\section{Activities of AEESEAP in Malaysia}

\subsection{The AEESEAP Secretariat}

The seat of the AEESEAP Secretariat is to rotate between the 15 voting member countries every 3 years. Currently, for the session of January 2004-December 2006, the AEESEAP Secretariat is held by The Faculty of Engineering, University of Malaya.

The role of the Secretariat is to coordinate all AEESEAP activities during the assigned period. Amongst the activities coordinated and organised by the AEESEAP Secretariat are:

- To organize conferences, workshops and seminars with the intention of improving the quality of engineering education in the region.

- To facilitate the dissemination of information and knowledge to member institutions, through printed and electronic media.

- To provide a common platform for discussion between engineering education institutions, industries and professional engineering bodies, in order to address current problems faced in engineering education.

- To promote collaborative research between member countries and between engineering education institutions and industries.

As a means to assist in achieving these objectives, the following committees have been set up within the AEESEAP secretariat:

1. The conference committee

2. The training committee (for short courses, training programmes, etc)

3. The publications committee

4. The excursions committee (for educational exchange visits)

5. The publicity committee 
As further course of action, the Secretariat has taken the initiative to include other Engineering Education Institutions in Malaysia. This step is timely, as the field of engineering education in Malaysia is an emerging topic which is of primary interest. The associate members in Malaysia have now been extended to:

- Universiti Kebangsaan Malaysia (UKM)

- Universiti Malaysia Sarawak (UNIMAS)

- Malaysian Multimedia University (MMU)

- Universiti Institut Teknologi Malaysia (UiTM)

- Kolej Universiti Teknologi Tun Hussein Onn (KUiTTO)

- Universiti Putra Malaysia (UPM)

Meetings are held quarterly, and all decisions pertaining to the AEESEAP activities in Malaysia involve input from these associate members, who are enrolled as members of the Secretariat. One of the pertinent issues faced by the Secretariat is the issue of sustainability, i.e. to sustain and develop AEESEAP's activities to achieve its aims and objectives. Two of the main activities in AEESEAP, the AEESEAP Conference and the AEESEAP Journal will be presented in Sections 4.2 and 4.3, respectively, and the sustainability of the association's activities will be discussed further in Section 4.4 .

\subsection{The AEESEAP Conference 2005}

The AEESEAP Conference for 2005 was titled, "Engineering A Better Environment for Mankind" and was held on June 7-9, 2005 in Kuala Lumpur. Its objectives were as follows:

1. To provide a prestigious international forum for stimulating presentations and interactions for engineering educationists. The conference theme provides a common platform for these educationists, to demonstrate the impact that engineering has on the environment and society.

2. To promote interdisciplinary discussions and collaborations between the different engineering disciplines, through the dissemination of technical knowledge and sharing of experiences.

The purpose of this conference is to provide an international forum for engineering educationists, to present recent results and developments with regards to the positive impact that engineering has on the environment in particular, and on society in general. The topics presented included:

- Engineering Education

- Electrical and Electronic Engineering

- Telecommunications Engineering

- Mechanical Engineering

- Chemical Engineering

- Civil Engineering

- Manufacturing Engineering

- Environmental Engineering

The conference attracted 107 participants including those from the Philippines, India, Bangladesh and India, amongst others. The conference also included two half-day workshops on academic writing and curriculum assessment, of which the participants found tremendously useful in helping to hone their skills on the respective topics. The conference was successful in garnering interest in the current developments in the field of Engineering Education in the region. 


\subsection{The AEESEAP Journal}

The AEESEAP Journal was published as a biennial journal, under the editorial management helmed at the Faculty of Engineering, University of Malaya. The list of editorial board members and referees were selected from the member institutions. The maiden edition published under the Malaysia Secretariat was launched in November 2005. The contents of the journal contained papers pertaining to Engineering, with an emphasis on Engineering Education. The initial selection was from the collection of papers presented at the AEESEAP Conference 2005 described above. However, there was considerable interest from academics from the member institutions, and the submissions were extended to those other than the conference papers for subsequent issues.

\subsection{Sustainability of AEESEAP}

The activities of AEESEAP are organized with the aid of funding from an existing account, which is managed by the Secretariat, i.e. it is the responsibility of the Secretariat in term to ensure that the funding is sufficient for the activities organized under the auspices of AEESAP. Therefore, the Secretariat must aim to sustain the activities of the association in the long run, bearing in mind the financial constraints of running such activities. Member institutions are encouraged to implement collaborative activities on a cost-sharing basis. Furthermore, since engineering education is not only the domain of engineering education institutions but also industry and governments, there is the possibility of seeking financial assistance to run these activities, from foundations and companies who are willing to support these relevant activities.

In order to ensure the success of the AEESEAP activities in achieving the aims and objectives of the association, there are a few pertinent indicators of success which will be discussed as follows:

\section{Cooperation of Member Institutions}

Deans or representatives from each member institution must actively participate in the committee's activities. One of the challenges that the Secretariat realised during the running of the secretariat is that the representatives of the institutions keep changing on a regular basis, and therefore, it is sometimes difficult for us to trace the responsible personnel. This raises difficulties in disseminating information and obtaining feedback from the member institutions, for example in obtaining response for contributions to the AEESEAP Journal and conferences.

\section{Quality of Output}

Quality outcomes for the association's activities are a prerequisite for sustainability. With reference to the association's core activities mentioned above, it is the Secretariat's aims to maintain the standards of these activities. For example, in the case of the AEESEAP journal, the aim is for at least $60 \%$ of the publications to be specifically under the topic of Engineering Education, and there is continous effort to reach out and solicit contributions from most member institutions. Similarly, for the AEESEAP conferences, it is the secretariat's aim to achieve an attendance profile which is truly international and reflects the member's institutions' involvement.

\section{Human Networking}

The key to successfully sustaining AEESEAP's activities lies in the strength of its human networking. Frequent and effective contact between the staff in each member institutions through the platform of AEESEAP should act as a driving force in promoting collaborations between interested members. This will spur on active 
exchange of ideas and collaborations in the interest of Engineering Education. The Secretariat is actively reaching out to its members through constant dissemination of information of the association's activities, through written and electronic media, and the association's website. However, these efforts must be a two way communication, and it is hoped that these efforts will be reciprocated by the member institutions, in order for the association's activities to be fully successful and sustainable.

\subsection{Sustainability with partnership for mutual benefits}

Based on our discussion so far regarding the activities of AEESEAP and efforts made to sustain it, it is evident that a strong partnership between the member institutions is necessary. For example, the member institutions from the less developed member countries have difficulty in fully participating in AEESEAP activities outside their countries, due to their lack of funding. This is where the assistance from the more developed countries can be of immense benefit. Such aids cannot be quantified in monetary terms per se, but can be viewed as a long term investment for future partnerships between different member institutions. It is a win-win situation, as both parties will benefit from such a partnership, in terms of exchange of ideas, research facilities and contribution of expertise.

\section{Conclusions}

This paper has outlined the origins, objectives, and activities of AEESEAP. The current activities helmed by the secretariat in Malaysia, was highlighted. There has been considerable effort in generating and sustaining the activities of AEESEAP, with the intention of promoting an interest in Engineering Education in Malaysia and in the region. A key issue encountered in the running of AEEEAP is the issue of sustainability, and this matter has been discussed at length in this paper. It is recognized that a key factor in sustaining AEESEAP lies in better communication and networking between the member institutions, in order to establish beneficial partnerships. It is hoped that the member countries can all work together in tandem with the Secretariat, in order to contribute towards greater interest in Engineering Education in Malaysia and the region.

\section{Acknowledgments}

The Malaysian AEESEAP Secretariat, based at the Faculty of Engineering, University of Malaya, would like to thank all member institutions in AEESEAP for entrusting them with the responsibility of coordinating the association's activities between 2004 and 2006.

\section{References}

AEESEAP webpage http://www.aeeseap.org

http://aeeseap.massey.ac.nz

\section{Biography}

Nasrudin Abdul Rahim received the BSc(Hons), M.Sc degrees from the University of Strathclyde, U.K, in 1985 and 1987, respectively, and the PhD from the University of Heriott-Watt, U.K, in 1995. In 1987, he joined the Department of Electrical Engineering, Faculty of Engineering, University of Malaya, Malaysia, as a lecturer and he is currently a Professor. From 2004 to due date, he is a Deputy Dean (Research and Postgraduate Study), Faculty of Engineering, University of Malaya. He has published more than 200 research papers in refereed journals and conferences. His research interests are Power Electronic Converters, Electrical Drives, and control. Currently, he is a Secretary General of AEESEAP and a Chairman of the working group WG8 covering reluctance motors of the IEEE Motor SubCommittee. 